J. Lake Sci.(湖泊科学), 2009, 21(4): 570-578

http://www.jlakes.org. E-mail: jlakes@niglas.ac.cn

(C2009 by Journal of Lake Sciences

\title{
鄱阳湖流域径流模型*
}

\author{
刘 健 ${ }^{1,2}$, 张 奇 ${ }^{1 * *}$, 左海军 ${ }^{1,2}$, 靳晓莉 ${ }^{1,2}$, 李丽娇 ${ }^{1,2}$, 叶许春 ${ }^{1,2}$ \\ (1: 中国科学院南京地理与湖泊研究所, 湖泊与环境国家重点实验室, 南京 210008) \\ (2: 中国科学院研究生院, 北京 100049)
}

摘 要: 流域径流是鄱阳湖主要来水, 建立鄱阳湖流域径流模型对揭示湖泊水量平衡及其受流域自然和人类活动的影响具有 重要意义. 针对鄱阳湖-流域系统的特点: 流域面积大 $\left(16.22 \times 10^{4} \mathrm{~km}^{2}\right)$ 、多条人湖河流、湖滨区坡面人湖径流等, 研究了相应的模 拟方法, 建立了考虑流域土壤属性和土地利用空间变化的鄱阳湖流域分布式径流模型. 采用 6 个水文站 1991-2001 年的实测河 道径流对模型进行了率定和验证. 结果显示, 模型整体模拟精度较高. 其中, 赣江、信江和饶河均取得了较好的模拟结果, 月效 率系数为 $0.82-0.95$; 抚河和修水模拟精度略低, 为 $0.65-0.78$. 模型揭示了研究时段内年平均人湖径流总量为 $1623 \times 10^{8} \mathrm{~m}^{3}$, 其中, 赣江最多, 占 $47 \%$, 其次为信江和抚河, 分别占 $13 \%$ 和 $12 \%$, 湖滨区坡面人湖径流约占 $4 \%$, 其余 $24 \%$ 来自饶河、修水以及其 它人湖支流. 模型将用于评估流域下垫面或气候变化引起的人湖水量变化, 为湖泊水量平衡计算提供依据.

关键词: 湖泊-流域系统; 分布式径流模型; 湖泊水量平衡; 鄱阳湖

\section{A surface runoff model for Lake Poyang watershed}

\author{
LIU Jian ${ }^{1,2}$, ZHANG Qi $^{1}$, ZUO Haijun ${ }^{1,2}$, JIN Xiaoli ${ }^{1,2}$, LI Lijiao ${ }^{1,2}$ \& YE Xuchun ${ }^{1,2}$ \\ (1: State Key Laboratory of Lake Science and Environment, Nanjing Institute of Geography and Limnology, Chinese Academy of \\ Sciences, Nanjing 210008, P.R.China) \\ (2: Graduate School of Chinese Academy of Sciences, Beijing 100049, P.R.China)
}

Abstract: Hydrological modelling of surface runoff for Lake Poyang watershed is of significant importance since the surface runoff is the main source of water inflows of the lake. The hydrological model can be used to reveal the influences of changes of natural and human conditions in the watershed on the surface runoff and consequently on the water balance of the lake. Hydrological modeling of the Lake Poyang watershed is challenging due to the complexities of the system, e.g. the large size $\left(162.2 \times 10^{4} \mathrm{~km}^{2}\right)$ of the area with high heterogeneity of soil types and land uses, contribution of stream flow from multiple rivers to the lake, and the overland flow at lake-side zone. Relevant methods to simulate the above features were presented and a distributed hydrological model was developed in this paper for Lake Poyang watershed. The model was well calibrated and validated against the observed daily stream flows at six stations from 1991 to 2001 . The results were satisfactory inthe general model predictions, with high monthly efficiencies of $0.82-$ 0.95 for Ganjiang, Xinjiang and Raohe rivers. Accuracy of model prediction for Fuhe and Xiushui rivers was slightly lower, with efficiencies ranging from 0.65 to 0.78 . The model indicated that the average volume of annual surface runoff to the lake for the simulation period was 162.3 billion $\mathrm{m}^{3}$, of which Ganjiang, Xinjiang and Fuhe rivers contributed $47 \%$, 13\% and $12 \%$, respectively. Direct overland flow to the lake at the lake-side zone accounted for about $4 \%$. The rest $(24 \%)$ was contributed via Raohe, Xiushui rivers and several tributaries. The model successfully simulated the hydrological processes of Lake Poyang watershed, and can be used to evaluate impacts of human activities on water variability and water balance of Lake Poyang.

Keywords: Lake-watershed system; distributed runoff model; lake water balance; Lake Poyang

* 中国科学院知识创新工程重要方向项目(KZCX2-YW-337)、中国科学院重大项目(KZCX1-YW-08-01)和国家自然科学基 金(40871026, 40471018)联合资助. 2008-08-10 收稿; 2008-11-06 收修改稿. 刘健，男，1980 年生，博士研究生; E-mail: water_liujian@163.com.

** 通讯作者; E-mail: qzhang@niglas.ac.cn. 
鄱阳湖位于江西省北部，长江中下游交 接处南岸, 是我国最大的淡水湖泊. 其承接赣 江、抚河、信江、饶河及修水五大河之水，是 一个天然吞吐型、季节性湖泊(图 1). 鄱阳湖流 域三面环山, 由相互独立的五个子流域组成, 集水域面积 $16.22 \times 10^{4} \mathrm{~km}^{2[1]}$. 流域内山地占 $36 \%$, 丘陵占 $42 \%$, 岗地和平原占 $12 \%$, 水面占 $10 \%{ }^{[2]}$. 流域内地带性土壤是红壤 $(56 \%)$, 耕作 土主要是水稻土 $(12 \%)$, 另外还有黄壤 $(10 \%)$ 、紫 色土 $(3.3 \%)$ 以及其他类型的土壤 $(18.7 \%)^{[3]}$. 土 地利用类型以林地 $(61.1 \%)$ 为主, 其次为耕地 $(27.7 \%)$ 、水体 $(4.7 \%)$ 、草地 $(4.3 \%)$ 、建筑用地和 未用地 $(2.2 \%)$ (数据统计于 2000 年江西省 1:1000000 土地利用类型数据). 鄱阳湖流域属 亚热带湿润季风气候, 降水丰富, 多年平均降 雨量为 $1620 \mathrm{~mm}$, 蒸发量在 $700-800 \mathrm{~mm}^{[2]}$. 流域 内降雨径流时空分布不均, 年内、年际变化明显, 具有明显的季节性和区域性，且洪旱灾害频繁 ${ }^{[4]}$. 赣江等“五河”多年(1952-1994 年)平均径流 量占全流域人湖总水量的 $85.4 \%$, 其余来自湖 面降水和长江倒灌 ${ }^{[5]}$. 鄱阳湖流域面积巨大, 流 域内土地利用类型和土壤类型分布空间差异性 大, 流域内人类活动剧烈, 气候变化较为异常 [3]，这些因素对流域径流产生了很大的影响, 继而影响湖泊的水量平衡, 威胁湖泊湿地的正 常功能. 为了定量评估流域人类活动和气候变 化对径流的影响, 揭示湖泊与流域的关系, 有 必要建立鄱阳湖流域径流模型. 采用水文模型 揭示流域水循环和径流过程对自然和人类活动 的响应也是目前国际上常用的研究手段 ${ }^{[6]}$. 鄱 阳湖-流域系统的主要特点有: (1)流域面积大, 下垫面自然属性空间变异大; (2)流域由 5 个相 互独立的子流域组成, 湖泊与 5 条主要河流(“五 河”)存在水力联系; (3)湖滨带人湖径流, 这部分 径流难于现场观测, 只能通过模拟的方法获得. 本文的研究目的是, 针对上述特点, 提出相应 的模拟方法, 建立鄱阳湖流域径流模型; 率定 模型, 并利用模型, 模拟入湖总地表径流以及 各河流径流(包括湖滨带坡面流)所占的比重, 为下一步湖泊水量平衡研究提供依据.

\section{1 模拟方法}

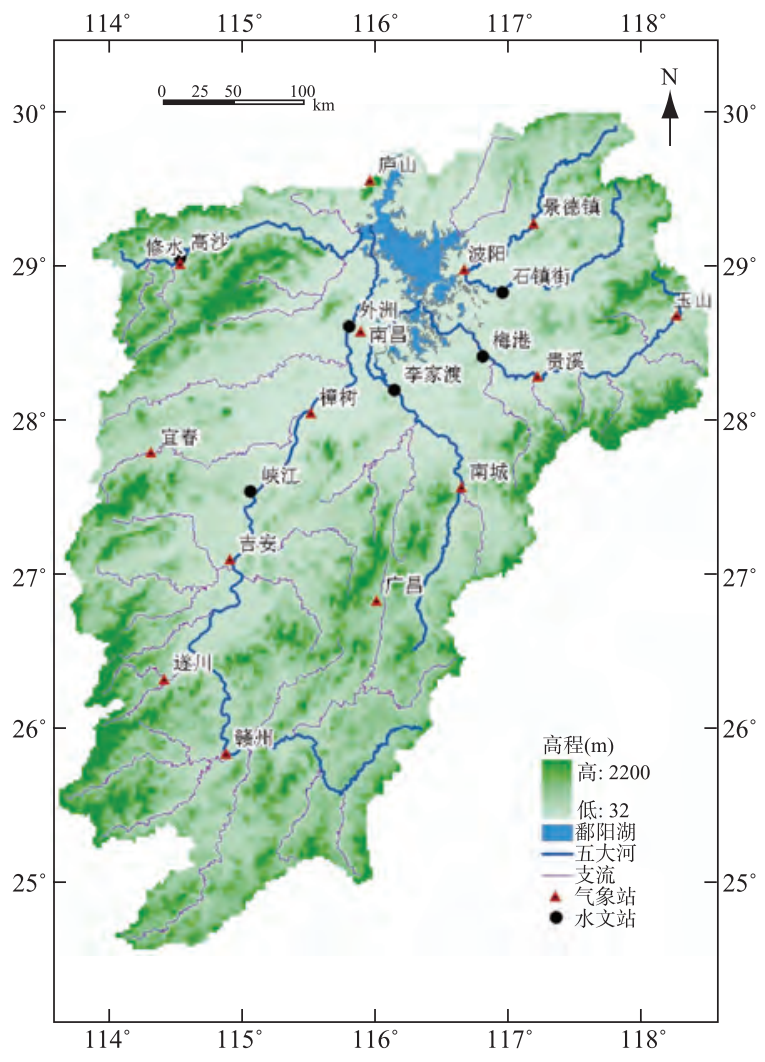

图 1 鄱阳湖流域及气象水文站点简图

Fig.1 Lake Poyang watershed and locations of climate and stream flow gauging stations

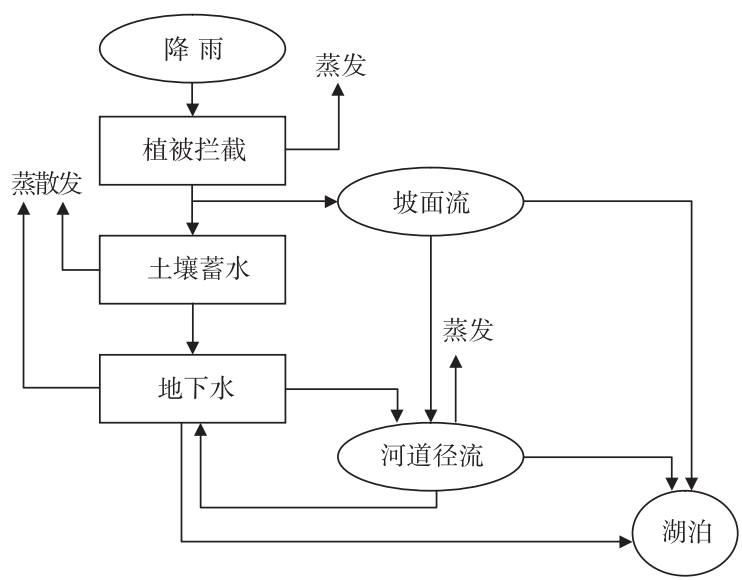

图 2 模型模拟的水流过程

Fig.2 Schematic diagram of water flow processes simulated in the model

\section{1 流域自然属性空间变异的模拟}

分布式水文模型考虑了降雨、蒸发和下垫面条件的空间分布不均匀性，能够便利地反映这些因素对 
径流的影响 ${ }^{[7]}$. 特别是近年来, 随着计算机和地理信息系统等相关技术的发展, 使得分布式模型的应用 越来越多 ${ }^{[8-15]}$. 本文模型模拟在降雨和蒸发驱动下, 流域的地表、地下径流径流过程. 具体过程包括, 植 被拦截、土壤蓄水、地表径流、土壤对地下水的补给等, 如图2示. 模型通过对研究区域的栅格化离散, 实 现对流域空间信息的模拟 ${ }^{[10-11]}$. 综合考虑流域土地利用和土壤类型分布特点以及流域尺度，采用了 $4 \mathrm{~km} \times 4 \mathrm{~km}$ 尺寸的网格单元模拟土地利用和土壤类型的空间分布(图3，图4). 在计算产、汇流中，单元被分 为三类, 一类是坡面流单元, 即模拟坡面产汇流; 第二类是河流单元, 模拟河道汇流及基流; 第三类是湖 -陆交界单元(湖泊水面与流域陆地的交汇线), 用于计算湖滨带直接人湖的坡面水流. 流域的空间属性由 网格单元反映, 即不同的单元赋予不同的流域属性(土地利用和土壤类型). 降水和蒸发条件通过空间插 值赋予单元, 在同一单元内, 流域自然属性和降雨、蒸发条件为恒定不变.

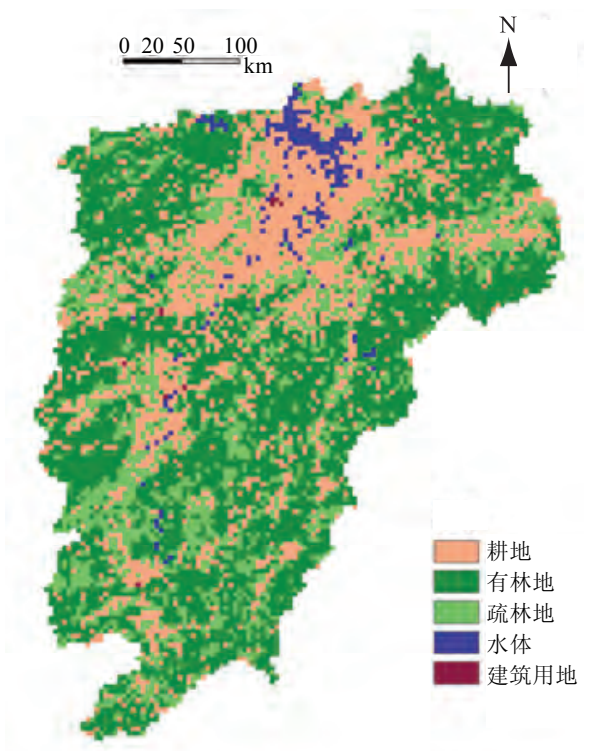

图 3 鄱阳湖流域土地利用类型空间离散图

Fig.3 Discretization of landuses in Lake Poyang watershed

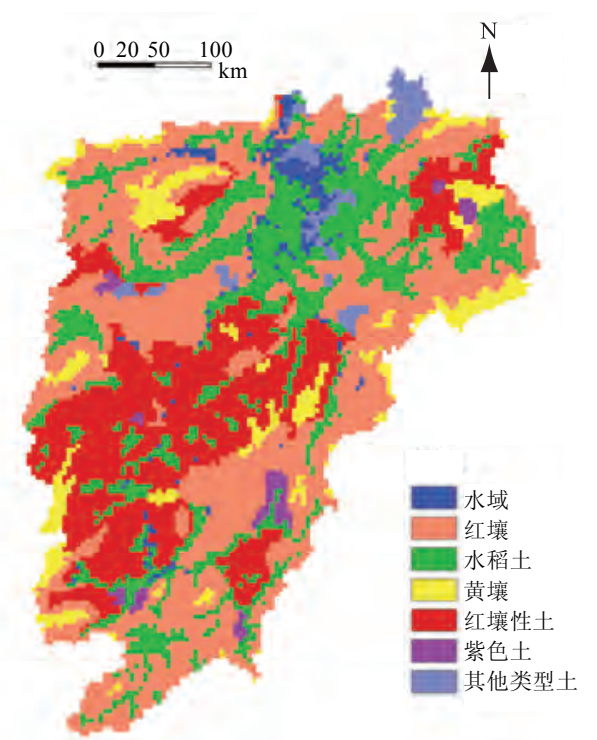

图 4 鄱阳湖流域土壤类型空间离散图

Fig.4 Discretization of soil types in Lake Poyang watershed

1.1.1 植被拦截 不同土地利用类型对降雨拦截存在差异. 引人潜在植被拦截量 $\left(V_{\mathrm{pci}}\right)$, 如下式计算:

$$
V_{\mathrm{pci}}\left(t_{i}\right)=V_{\mathrm{mci}}\left(t_{i}\right)-S_{\mathrm{c}}\left(t_{i-1}\right)
$$

式中, $V_{\mathrm{mci}}$ 为最大植被拦截量 $(\mathrm{mm})$, 与土地利用类型有关; $S_{\mathrm{c}}$ 为植被冠层蓄水量 $(\mathrm{mm}) ; t_{i-1}$ 和 $t_{i}$ 分别表示上 一个时间步长和当前时间步长. 本模型以日为时间步长.

实际植被拦截量 $\left(V_{\mathrm{aci}}\right)$ 为潜在植被拦截量和大气降雨量中的较小值. 扣除实际植被拦截量后可获得到 达地面的净降雨量, 用于计算地表产流.

植被拦截消耗于蒸发, 实际蒸发量 $\left(E_{\mathrm{ac}}\right)$ 为植被现时蓄水量 $\left(\right.$ 为前期植冠蓄水量 $S_{c}\left(t_{\mathrm{i}-1}\right)$ 和现时拦截量 $V_{\mathrm{aci}}\left(t_{i}\right)$ 之和)和潜在蒸发量的最小值 ${ }^{[16]}$, 潜在蒸发量由蒸发血观测数据通过引人蒸发血折算系数 ${ }^{[17]}$ 获得.

1.1.2 土壤蓄水及产流量 土壤类型通过引人土壤蓄水系数加以反映. 定义土壤层的最大蓄水容量与土层 高度成线性关系, 线性系数即为土壤蓄水系数:

$$
S_{\mathrm{mss}}(t)=\theta \cdot h_{\mathrm{s}}(t)
$$

式中, $S_{\mathrm{mss}}(t)$ 是土壤最大蓄水容量 $(\mathrm{mm}) ; \theta(0 \leqslant \theta \leqslant 1)$ 为土壤蓄水系数, 反映土壤的蓄水能力, 是无量纲参数; $h_{\mathrm{s}}(t)$ 是土层高度 $(\mathrm{mm})$, 由获得的数据库获得, 如果地下水位以上土体厚度小于 $h_{\mathrm{s}}$, 那么计算中的实际高度 为地面到饱和地下水自由面的距离, $h_{\mathrm{s}}(t)=Z_{\mathrm{top}}-h(t), Z_{\mathrm{top}}$ 是地面高程; $h(t)$ 是地下水自由面高程, 由地下水模 
拟求得; $t$ 是当前时段.

对土壤来说，其来水量是地面净降雨(大气降雨减去植被拦截)和地面上已有的积水，蒸散发和向地 下水补给为其排水条件. 在模型中定义潜在土壤人渗率如下式计算:

$$
V_{\mathrm{psi}}\left(t_{i}\right)=V_{\mathrm{msi}}\left(t_{i}\right) \cdot\left[1-S_{\mathrm{s}}\left(t_{i-1}\right) / S_{\mathrm{mss}}\left(t_{i}\right)\right]
$$

式中, $V_{\mathrm{psi}}$ 是潜在土壤人渗率; $V_{\mathrm{msi}}$ 是最大土壤人渗率, 主要与土地利用类型有关; $S_{\mathrm{s}}$ 是起始土壤蓄水量.

实际土壤人渗量为潜在人渗量、地面蓄水量和土壤可供蓄水容量(即土壤可用于蓄水的空余容量)三 者的最小值. 地面蓄水量扣除实际土壤人渗量后, 即为地表径流量.

土壤水一部分消耗于蒸发, 定义实际蒸发量为土壤蓄水量 $\left(S_{\mathrm{s}}\right)$ 和潜在蒸发量的最小值 ${ }^{[16]}$, 潜在蒸发 量计算如前.

土壤水另一部分下渗为地下水补给量, 该补给量假设为与土壤含水量成正比 ${ }^{[18-19]}$. 通过引入最大地 下水补给率, 潜在地下水补给率 $\left(R_{\mathrm{pg}}\right)$ 可由下式计算:

$$
R_{\mathrm{pg}}\left(t_{i}\right)=R_{\mathrm{mg}}\left(t_{i}\right) \cdot S_{s}^{\prime}\left(t_{i}\right) / S_{\mathrm{mss}}\left(t_{i}\right)
$$

式中, $R_{\mathrm{mg}}$ 是最大地下水补给率, 需要通过模型率定获得; $S_{s}^{\prime}$ 是当前时段的土壤含水量. 实际地下水补给 率, $R_{\mathrm{ag}}$ 是潜在地下水补给率和土壤含水率中的较小值. 在计算得到土壤向地下水的补给率后, 再考虑土 壤水分的实际蒸散发, 就可以得到时段末土壤含水量.

1.1.3 坡面流与河道径流 坡面流根据DEM数据按照D8法计算产流路径，并通过变蓄量法或马斯京根法 计算河道汇流，坡面流和河道径流水流速度由曼宁公式计算获得 ${ }^{[8]}$ :

坡面流:

河道径流:

$$
v_{\mathrm{o}}=\left(q_{\mathrm{o}}^{0.4} \cdot l_{\mathrm{o}}^{0.3}\right) / n_{\mathrm{o}}^{0.6}
$$

$$
v_{\mathrm{s}}=\left(0.489 \cdot q_{\mathrm{s}}^{0.25} \cdot l_{\mathrm{s}}^{0.375}\right) / n_{\mathrm{s}}^{0.75}
$$

式中, $o$ 和 $s$ 分别代表坡面流和河道径流; $v$ 为流速 $(\mathrm{m} / \mathrm{s}) ; l$ 为流径坡度 $(\mathrm{m} / \mathrm{m}) ; n$ 曼宁粘率系数; $q$ 为单位宽 流径流量 $\left(\mathrm{m}^{3} /(\mathrm{m} \cdot \mathrm{s})\right)$, 由 $q=R^{\prime} \cdot L_{k} / 1000 / 24 / 3600$ 计算, 其中, $L_{k}(\mathrm{~m})$ 是沿水流方向, 单元 $k$ 到相邻单元的坡长.

坡面流和河道径流均引人指数方程考虑滞后. 对单位宽度的流段:

$$
R^{\prime}(t)=\left[R_{\mathrm{sro}}(t)+R_{\mathrm{store}}(t-1)\right] \cdot\left[1-\exp \left(-C_{\text {lag }} / T\right)\right]
$$

式中, $R$ 为当前时段从一单元流向下一单元的径流量 $(\mathrm{mm}) ; R_{\mathrm{sro}}$ 为当前时段产生的径流量 $(\mathrm{mm}) ; R_{\text {store }}$ 为上 一时段滞留径流量量 $(\mathrm{mm}) ; C_{\mathrm{lag}}$ 为滞后系数; $T$ 为水流从一单元流向下一相邻单元时间(h).

基流由地下水模拟及其与河道的水量交换计算获得，具体由 MODFLOW 及其河流软件包(RIV Package) 实现 ${ }^{[21]}$, 同时定义饱和渗透系数 $K$ 各向同性.

\section{2 湖泊与五条河流的联系}

目前已有的模型多局限于具有单一出口断面的流域, 比如 TOPMODEL ${ }^{[9]} 、 \mathrm{LASCAM}^{[22]}$ 等, 这类模型 在模拟多河流出流时有很多不便或不适用，也很难应用到鄱阳湖流域. 为此, 本文采用了一种适应性更 好的地表径流汇流路径算法，即可在模型包括若干个相对独立的河流流域，每个河流流域具有自己的出 口断面, 各河流的流域边界由模型自动计算, 省去了人为构画边界的工作. 具体计算步骤为: 数字地形 高程模型(DEM)预处理，检验错误信息并做填洼处理; 采用D8单流向算法 ${ }^{[23]}$, 计算各单元水流方向; 根 据水流方向, 对单元进行排序, 计算汇流路径; 根据各汇流路径的上下游关系和交汇方式, 确定汇流路 径的级别，以此作为计算各路径径流量的先后次序. 在汇流路径的计算中，算法并不要求所有路径最后 汇集到单一的出口断面，而能对各河流流域作独立区分计算, 分别计算各河流的流域面积和边界.

鄱阳湖流域除赣江等五大水系外，在环湖区还有 10 条直接人湖河流，其中 3 条河的集水面积相对较 大, 分别为清丰山溪、西河和潼津水 ${ }^{[24]}$. 由于清丰山溪流至南昌县吴石镇前渡槽进人抚河故道及贑抚平 原渠系 ${ }^{[24]}$, 所以本文将其水量并人抚河水系. 本文仅选择西河和潼津水作为环湖区人湖河流, 并做了模 拟，其余7条较小的直接人湖河流并人坡面流.

模型分别定义了五大河流和两条环湖区河流共7个出口断面，断面位于河流与湖泊的交汇点. 每个 
断面表示一个独立流域的出口.

\section{3 湖滨带坡面径流模拟}

湖滨带的坡面流难于现场观测, 往往通过模型模拟计算. 在湖泊水体与周围陆地的交界处, 定义湖陆交界单元来模拟流域与湖泊的连接. 这类湖-陆交界单元在模型中被处理为坡面流的汇，即坡面流路 径的最后一个单元, 汇人该单元的径流都被计人人湖径流. 鄱阳湖水位季节性变化明显, 在本次模拟中, 选取鄱阳湖较高水位 (湖口水位 $21.71 \mathrm{~m}$, 湖面面积 $\left.3283 \mathrm{~km}^{2}\right)^{[5]}$ 作为模拟条件, 暂不考虑水位的波动.

模型详细过程可参阅文献[18]、[19]和[20].

\section{2 模型建立}

为了检验上述模拟方法的有效性，本文选取鄱阳湖流域1991-2001年间的径流观测数据对模型模拟 效果进行评价，其中1991-1995年为率定期，1996-2001年验证期. 模型模拟陆地集水域面积 $15.49 \times 10^{4} \mathrm{~km}^{2}$, 包括赣江等“五河”干流及其36条主要支流, 还有环湖区两条人湖河流(西河和潼津水).

\section{1 基础数据}

模型输人数据主要分为降雨和蒸发、地形高程(DEM)、水系、土地利用类型以及土壤属性五类. (1) 降水和蒸发数据选取流域内 14 个国家气象站(图 1)1991-2001年逐日实测数据, 所有数据均通过均一性检 验 (95\%置信度); (2)地形数据由 1:250000 等高线矢量数据应用 ArcGIS 软件插值生成 DEM 数据; (3)水系 数据由生成的 DEM 数据应用 ArcGIS 软件提取, 并根据江西省水系图片修正获得; (4)土地利用类型数据 由江西省 2000 年 1:1000000 土地利用图片数字化得到, 并根据不同类型的面积及其对产流贡献, 选取了 耕地、有林地(郁闭度 $>30 \%$ )、疏林地(郁闭度 $<30 \%$ )、水域以及建筑用地共 5 种类型(图 3); (5)土壤类型(图 4)属性数据包括土体厚度和土壤总空隙度, 根据中国科学院土壤所提供的数据库, 土体厚度(即公式(2)中 $h_{s}$ ) 定为 $70 \mathrm{~cm}$, 鄱阳湖流域红壤、水稻土、黄壤、红壤性土、紫色土和其他类型土总孔隙度分别为 0.48 、 $0.41 、 0.52 、 0.50 、 0.46 、 0.47^{[25-27]}$.

选取鄱阳湖流域六个水文观测站(图 1)对模拟结果进行检验. 其中, 赣江流域选取下游的外洲站(控 制面积 $8.09 \times 10^{4} \mathrm{~km}^{2}$ ) 和中游的峡江站(控制面积 $6.27 \times 10^{4} \mathrm{~km}^{2}$ ); 抚河流域选取李家渡站(控制面积 $1.58 \times 10^{4} \mathrm{~km}^{2}$ ); 信江流域选取梅港站(控制面积 $\left.1.55 \times 10^{4} \mathrm{~km}^{2}\right)$; 饶河流域选取乐安河下游的石镇街站(控制 面积 $0.84 \times 10^{4} \mathrm{~km}^{2}$ ), 修水流域选取上游的高沙站(位于柘林水库上游, 控制面积 $0.53 \times 10^{4} \mathrm{~km}^{2}$ ).

\section{2 模型率定}

采用“试错法”(trial-and-error)进行率定. 在鄱阳湖流域的五个子流域中，由于信江流域相比于其它流 域水利工程少, 水资源的时空分布受人为影响较小, 降雨-径流关系符合自然规律. 所以, 在模型率定中, 该流域梅港站观测数据给予了较大的权重. 土地利用类型中的水域和建筑用地在模型中设定为不透水面 积, 其最大植被拦截量 $V_{\mathrm{mci}}$ 和最大土壤人渗率 $V_{\mathrm{msi}}$ 值都定为 0 , 而对于有林地、疏林地和耕地三种类型则 具有不同的 $V_{\mathrm{mci}}$ 和 $V_{\mathrm{msi}}$ 值. 本文采用文献[28]中的方法对参数进行率定，即假定有林地等三种类型的同一 参数分别按相同的比例因子增大或减少, 经过调试, 比例因子为 1.2 左右较为合适. 最终确定有林地、疏 林地和耕地的 $V_{\mathrm{mci}}$ 和 $V_{\mathrm{msi}}$ 值分别为 $1.5 、 1.2 、 1.0 \mathrm{~mm} / \mathrm{d}$ 和 $35.0 、 30.0 、 26.0 \mathrm{~mm} / \mathrm{d}$. 最大地下水补给率 $R_{\mathrm{mg}}$ 和含水层饱和渗透系数 $K$ 主要控制地下水位, 进而影响基流量. 分别应用 HYSEP 分割方法中的局部最小 值法和数字滤波法中的第三类方法 ${ }^{[28]}$ 来分割外洲等六个水文站的日径流观测值, 得基流占总河道径流的 百分比平均值为 $46 \%$, 根据此数据来率定地下水模型中的基流量. 经过率定, 在模型中所有土壤类型的 $R_{\mathrm{mg}}$ 和 $K$ 都采用均一值, $R_{\mathrm{mg}}$ 值和 $K$ 值分别定为 $3.5 \mathrm{~mm} / \mathrm{d}$ 和 $20.0 \mathrm{~m} / \mathrm{d}$.

模型输出了六个水文站的日径流过程. 采用效率系数 $e\left(e=1-V_{\mathrm{r}} / V_{\mathrm{o}}\right), V_{\mathrm{r}}$ 为观测值与模拟值的差的方差, $V_{\mathrm{o}}$ 为观测值的方差, $e$ 的范围为 1 至- $\infty$, 分别表示 “最优”至 “最差”的吻合 ${ }^{[29]}$ 和多年径流统计量相对误差 $r$ 作为模拟结果的评价指标. 表 2 分别列举了 6 个水文站的日、月和年径流效率系数 $e$ 和多年径流统计 量相对误差 $r$. 图 5 和图 6 为率定时段内水文站径流模拟值和观测值的比较. 限于篇幅, 这里只展示外洲 站和梅港站 1992 年日径流过程比较(图 5)和 6 个水文站月径流过程比较(图 6). 赣江的外洲和峡江站的日 径流模拟效率系数为 0.79 和 0.75 , 效果一般. 由图 5 可知, 外洲站的洪峰模拟值存在一定误差, 这可能是 
万安水库(总库容 $\left.22.16 \times 10^{8} \mathrm{~m}^{3}\right)^{[3]}$ 对径流调节作用的影响. 而月、年径流受水库的影响较小, 故月、年效率 系数以及多年径流统计量相对误差模拟效果较好, $e$ 在 0.87-0.96 之间, $r$ 为 $2.2 \%$ 和 3.5\%. 图 6 中外洲站和 峡江站的月径流模拟结果和实测结果吻合良好. 抚河的李家渡水文站日径流 $e$ 仅为 0.37 , 月、年径流 $e$ 为 0.78 和 0.77 , 多年径流统计量模拟值比观测值高 $42.6 \%$ (图 6). 主要原因可能是抚河流域的中上游建有 大型水库一洪门水库(总库容 $12.2 \times 10^{8} \mathrm{~m}^{3}$ ), 中下游建有金临渠、赣抚平原总干渠 (有效灌溉面积 $6.7 \times 10^{8} \mathrm{~m}^{2}$ ) 等水利设施, 水资源利用程度极高造成的 ${ }^{[3]}$. 信江流域无大型水库, 无严重的人为干扰, 所以梅港站的 日、月和年径流模拟效率系数均较高, 多年径流相对误差较低, 仅为 $0.9 \%$. 饶河流域的乐安河由于中游 共产主义水库的影响，石镇街站日径流模拟 $e$ 为 0.72 , 但月和年模拟效果较好, $e$ 达到 0.90 和 0.84 ; 多年 径流量相对误差为 $12.3 \%$. 图 6石镇街站的月径流模拟值和观测值吻合良好. 修水的高沙站径流模拟效果 一般, 日径流模拟效率系数为 0.62 ; 月和年效率系数也只有 0.65 和 0.69 , 并且多年径流统计量模拟值低 于观测值 $53.6 \%$. 从图 6 的高沙站比较图也可以看出, 月径流模拟结果要低于实测结果. 这可能是因为高 沙站控制面积只有 $0.53 \times 10^{4} \mathrm{~km}^{2}$, 而本文采用的 $4 \mathrm{~km}$ 网格尺寸相对较大，不能准确模拟流域边界和汇水面 积引起的误差.

表 1 率定期各水文站的评价指标值*

Tab.1 Model efficiency evaluation at six stream gauging stations for the calibration period

\begin{tabular}{ccccccc}
\hline \multirow{2}{*}{ 子流域 } & \multirow{2}{*}{ 水文站 } & 控制面积 & \multicolumn{3}{c}{ 效率系数 $e$} & 多年径流统计量 \\
& & $\left.\times 10^{4} \mathrm{~km}^{2}\right)$ & 日 & 月 & 年 & 相对误差 $r(\%)$ \\
\hline 赣江流域 & 外洲站 & 8.09 & 0.79 & 0.91 & 0.87 & 2.2 \\
& 峡江站 & 6.27 & 0.75 & 0.90 & 0.96 & -3.5 \\
抚河流域 & 李家渡站 & 1.58 & 0.37 & 0.78 & 0.77 & 42.6 \\
信江流域 & 梅港站 & 1.55 & 0.82 & 0.95 & 0.95 & 0.9 \\
饶河流域 & 石镇街站 & 0.84 & 0.72 & 0.90 & 0.84 & -12.3 \\
修水流域 & 高沙站 & 0.53 & 0.62 & 0.65 & 0.69 & -53.6 \\
\hline
\end{tabular}

* $r$ 正表示模拟值高于实测值, 负表示模拟值低于实测值.
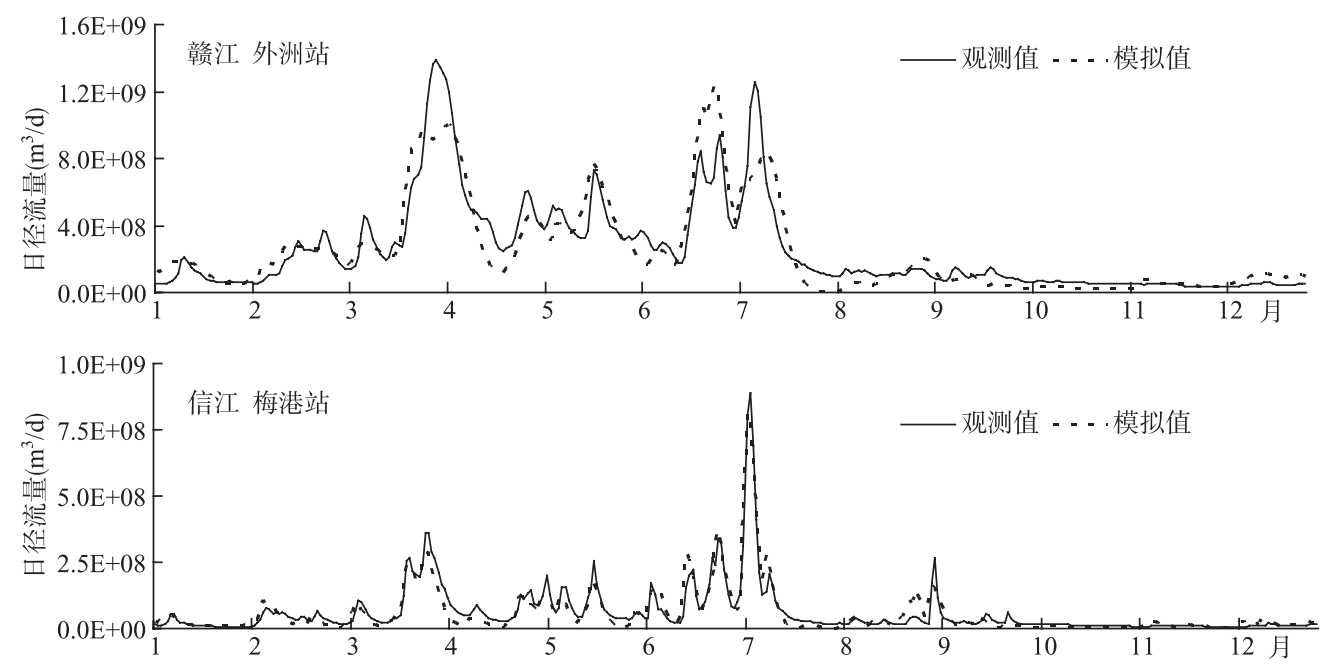

图5 1992年外洲站和梅港站日径流模拟值与观测值的比较

Fig.5 Comparison of modelled daily and observed stream discharges at Waizhou station and Meigang station in 1992 

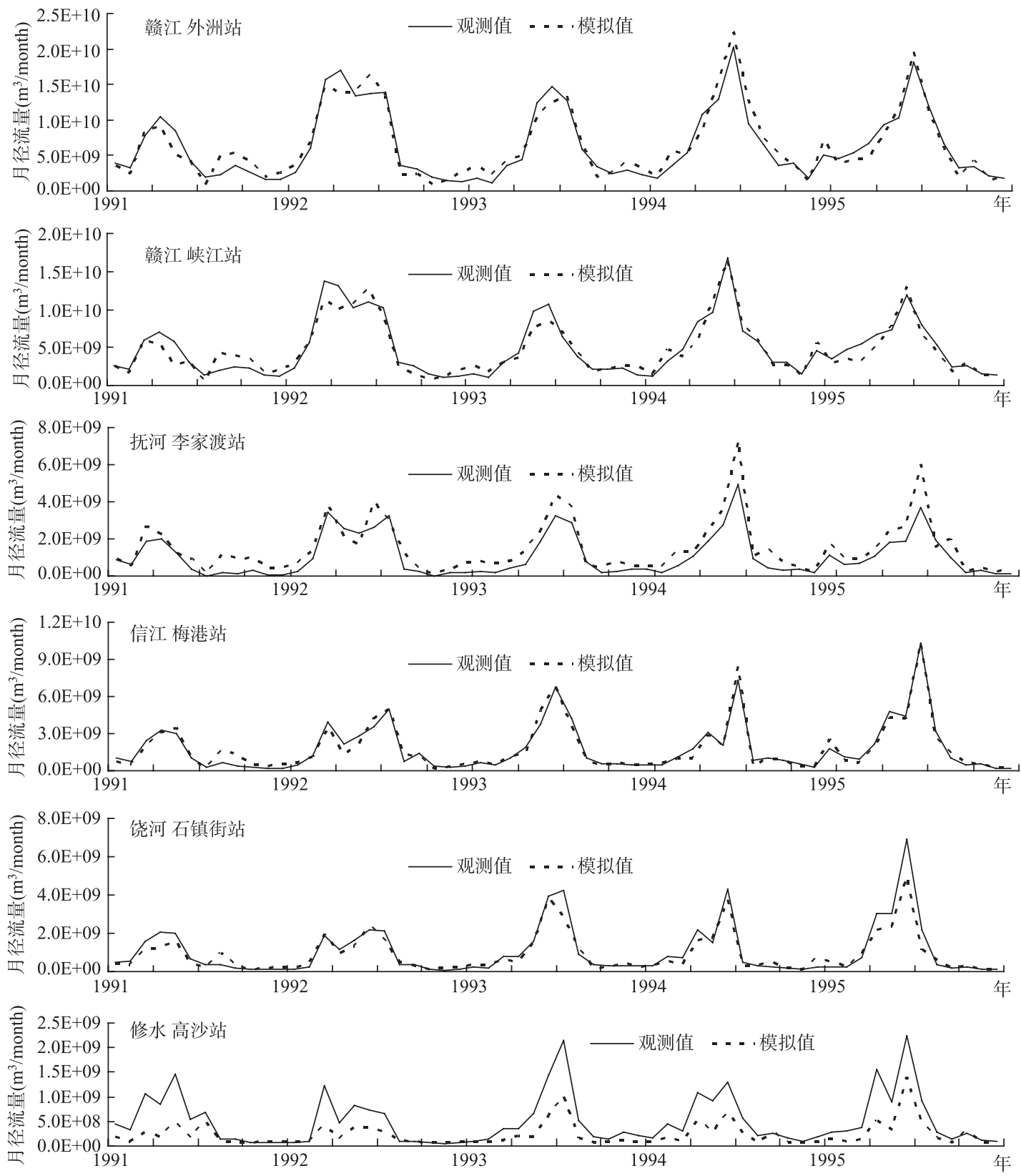

图 6 1991-1995 年 6 个水文站月径流模拟值与观测值的比较

Fig.6 Comparison of modelled monthly and observed stream discharges at six hydrological stations during 1991-1995

\section{3 模型验证}

应用率定的模型模拟1996年1月1日至2001年12月31日的径流过程，模型同样输出6个水文站的日径流. 分别对 6 个水文站的日、月和年径流的效率系数和多年径流统计量误差进行分析. 赣江的外洲和峡江站以及 饶河的石镇街站由于水库的影响，日效率系数在 0.70 左右，但月、年效率系数在 $0.82-0.92$ 之间，多年径流统 计量相对误差 $r$ 在 $1.9 \%-4.7 \%$ 之间, 模拟值与观测值较为吻合. 信江的梅港站日径流效率系数为 0.79 , 月、年 效率系数分别达到了 0.93 和 0.94 , 多年径流统计量相对误差为 $3.1 \%$, 取得了较好的模拟效果. 抚河的李家渡 站和修水的高沙站日效率系数仅为 0.43 和 0.62 , 月、年效率系数在 $0.72-0.91$ 之间, 多年径流统计量相对误差 
分别为 $43.1 \%$ 和 $53 \%$, 误差较大，原因在模型率定 中已作了分析.

\section{4 入湖水量分析}

在赣江等五大河和环湖区两河(西河和潼津 水)的最下游处(河流与湖泊的交汇点)设置控制断 面, 由模型输出各河流的径流量, 即为河流的人湖 流量. 分析整个研究时段(1991-2001 年)的径流, 可得出模型模拟的地表径流人湖总水量和“五河” 分别所占的比重(表 2). 可见, 五大河的来水量以 赣江最多, 其次为信江和抚河. 本文模拟的结果 均高于文献[5], 主要是由两方面原因造成的: 一 是，本文模拟时段为 1991-2001 年，而文献[5]计 算时段为 1952-1994 年. 鄱阳湖流域降水量在 1955-1989 年平均降水量呈现振荡状态, 无明显 趋势, 但是在 1990 后发生突变, 呈现明显上升趋 势. 1991-2002 年平均降水量比 1961-1990 年平均 降水量高出 $201.5 \mathrm{~mm}^{[30]}$; 第二, “五河”水系的径流系数均在 $1990 \mathrm{~s}$ 有所升高, 特别是赣江流域、饶河流域(乐 安河)、信江流域及修水支流潦河流域升高明显 ${ }^{[30]}$.

模型模拟的多年平均人湖径流量为 $1623.2 \times 10^{8} \mathrm{~m}^{3}$, 占年降水量的 $58.9 \%$. 其中赣江等五河年平均径 流量和为 $1523.2 \times 10^{8} \mathrm{~m}^{3}$, 占集水域总入湖径流量的 $93.8 \%$; 环湖区两人湖河流水量占集水域总入湖径流 量的 $2.6 \%$. 模型计算的湖滨带多年平均人湖水量为 $57.9 \times 10^{8} \mathrm{~m}^{3}$, 占集水域总人湖径流量的 $3.6 \%$.

\section{3 结论}

(1)针对鄱阳湖流域降雨-径流模拟存在的流域面积大，降雨-径流关系存在高度空间非均匀性; 整个 流域由 5 个相互独立的子流域组成，兼有多条人湖河流; 湖滨带坡面人湖径流等特点, 本文提出了相应的模 拟方法，并以此成功构建了鄱阳湖流域分布式水文模型. 本文所提出的模拟方法，对其它类似区域的研究 也具有重要参考价值.

(2)与实测径流的比较发现, 模型整体精度较高, 模型的有效性得到了验证. 其中, 赣江的外洲和峡江站、 饶河的石镇街站以及信江的梅港站均取得了较好的模拟效果，日效率系数在 0.70-0.79 之间，月、年效率系数 在 0.81-0.96 之间, 多年径流统计量相对误差在 1.9\%-12.3\%之间; 抚河的李家渡站和修水的高沙站模拟精度 略低，日效率系数在 0.37-0.62 之间，月、年效率系数在 0.65-0.91 之间，多年径流统计量相对误差在 42.6\%-53.6\%之间. 李家渡站模拟精度偏低主要由于抚河上游建有大型水库, 中下游建有灌渠等水利设施, 水 资源利用程度极高造成的. 而高沙站由于其控制的集水面积小, 模型模拟的集水面积可能带有较大误差.

(3)模拟结果显示，鄱阳湖流域研究时段内多年平均人湖径流量为 $1645.2 \times 10^{8} \mathrm{~m}^{3}$, 占年降水量的 $59.7 \%$. 其中, 赣江的贡献最大，占 $46 \%$, 其次是信江和抚河, 分别占 $13 \%$ 和 $12 \%$. 模型还揭示了湖滨带多 年平均径流量为 $57.9 \times 10^{8} \mathrm{~m}^{3}$, 约占总量的 $4 \%$.

(4)本文建立的鄱阳湖流域模型反映了流域属性的空间非均匀性，可用于定量评估流域人类活动(比 如, 土地利用变化等)对径流的影响; 通过与气候模型的耦合也可以模拟气候要素变化对流域径流, 乃至 湖泊水量平衡的影响.

致谢: 本次工作得到了中国气象局信息中心、长江水利委员会水文局、江西省山江湖开发治理委员会办 公室以及中国科学院南京地理与湖泊研究所姜形研究员的帮助, 在此一并致谢.

\section{4 参考文献}

[1] 戴星照, 方 豫, 陈葵花等. 鄱阳湖流域综合规划与管理技术. 江西科学, 2003, 21(3): 217-221.

[2] 樊述全. 鄱阳湖流域降雨时空分布规律及其水文响应[学位论文]. 南京: 河海大学, 2007. 
[3] 郭 华. 气候变化及土地覆被变化对鄱阳湖流域径流的影响[学位论文]. 南京: 中国科学院南京地理与湖泊研究所, 2007: 15-59.

[4] 郭 华, 姜 形, 王国杰等. 1961-2003 年间鄱阳湖流域气候变化趋势及突变分析. 湖泊科学, 2006, 18(5): 443-451.

[5] 朱海虹, 张 本. 鄱阳湖一一水文、生物、沉积、湿地、开发治理. 合肥: 中国科学技术大学出版社, 1997: 3-92.

[6] 茌孝芳, 蒋成显, 张金存. 流域水文模型的发展. 水文, 2006, 26(3): 22-26.

[7] 张金存, 芮孝芳. 分布式水文模型构建理论与方法评述. 水科学进展, 2007, 18(2): 286-292.

[8] Neitsch SL, Arnold JG, Kiniry JR et al. Soil and water assessment tool theoretical documentation, Version 2000. Texas Water Resources Institute, College Station, Texas, TWRI Report TR-191, 2002.

[9] Beven KJ, Kirkby MJ. A physically based variable contributing area model of basin hydrology. Hydrological Science Bulletin, 1979, 24: 43-69.

[10] Panday S, Huyankorn PS. A fully coupled physically-based spatially-distributed model for evaluating surface/subsurface flow. Advances in Water Resources, 2004, 27: 361-382.

[11] Abbott MB, Bathurst JC, Cunge JA et al. An introduction to the European Hydrological System-Système Hydrologique Européen "SHE”2: Structure of a physically based distributed modeling system. Journal of Hydrology, 1986, 87: 61-77.

[12] 赵人俊. 流域水文模型——安江模型与陕北模型. 北京: 水利电力出版社, 1984.

[13] 黄 平, 赵吉国. 流域分布型水文数学模型的研究及应用前景展望. 水文, 1997, (5): 5-10.

[14] 郭生练, 熊立华, 杨 井等. 基于DEM的分布式流域水文物理模型. 武汉水利电力大学学报, 2000, 33(6): 1-5.

[15] 贾仰文. WEP 模型的开发与应用. 水科学进展, 2003, 14(增刊): 50 - 56.

[16] US Army Corps of Engineers (USACE). Hydrologic modeling system HEC-HMS. Technical Reference Hydrologic Engineering Center, Davis, CA 95616-4687, USA, 2000.

[17] Xu CY, Gong L, Jiang T et al. Analysis of spatial distribution and temporal trend of reference evapotranspiration and pan evaporation in Changjiang (Yangtze River) catchment. Journal of Hydrology, 2006, 327: 81-93.

[18] 张＼cjkstart奇. 湖泊集水域地表-地下径流联合模拟. 地理科学进展, 2007, 26(5): 1-10.

[19] Zhang Q, Viney NR. Development and testing of a distributed hydrological model with comparison to a conceptual lumped model. Proceedings of Water Down Under 2008, incorporating 31st Hydrology and Water Resources Symposium and 4th International Conference on Water Resources and Environment Research, 14-17April 2008, Adelaide, Australia, 1319-1329. ISBN 0858257351, Engineers Australia, 2008.

[20] Zhang Qi, Li Lijiao. Development and application of an integrated surface runoff and groundwater flow model for a catchment of Lake Taihu watershed, China. Quaternary International, 2009(doi: 10. 1016/j.quaint. 2008.10.015).

[21] McDonald MG, Harbaugh AW. A modular three-dimensional finite-difference ground-water flow model. U.S. Geological Survey Techniques of Water-Resources Investigations, book 6, chap. A1, 1988.

[22] Viney NR, Sivapalan M. LASCAM: The large scale catchment model, User Mannual, version 2. Centre for Water Research, University of Western Australia, 2000.

[23] Jain MK, Singh VP. DEM-based modelling of surface runoff using diffusion wave equation. Journal of Hydrology, 2005, 302: 107-126.

[24] 熊小群, 杨荣清. 江西水系. 武汉: 长江出版社, 2007.

[25] 史学正，于东升，高＼cjkstart鹏等. 中国土壤信息系统(SIS China)及应用基础研究. 土壤, 2007, 39(3): 329-333.

[26] Shi XZ, Yu DS. Cross-reference system for translating between genetic soil classification of China and soil taxonomy. Soil Sci Am J, 2006, 70(1):78-83.

[27] Shi XZ, Yu DS. Soil database of 1:1000,000 digital soil survey and reference system of the Chinese Genetic Soil Classification System. Soil Survey Horizons, 2004, 45(4): 129-136.

[28] 刘 健, 张 奇. 一个新的分布式水文模型在鄱阳湖赣江流域的验证. 长江流域资源与环境, 2009, 18(1): 20-27.

[29] 张 奇, 李恒鹏, 徐力刚. 太湖西若溪流域径流过程的模拟. 湖泊科学, 2006, 18(4): 401-406.

[30] 郭 华, 苏布达, 王艳丽等. 鄱阳湖流域 1955-2002 年径流系数变化趋势及其与气候因子的关系. 湖泊科学, 2007, 19(2): 163-169. 